Miras, N. (2015). El controvertido fondo de capitalización y su posible tributación en España. Revista Lebret, 7. Bucaramanga, Colombia: Universidad Santo Tomás. pp. $39-60$. ISSN: 2145-5996.

\title{
El controvertido fondo de capitalización y su posible tributación en España*
}

\section{The controversial Capitalization Fund and its possible taxation in Spain}

Norberto Miras Marín

\begin{abstract}
Resumen
En estas líneas se resumen los principales rasgos que caracterizarán a la nueva figura del fondo de capitalización en España -conocido como fondo de cesantía en Colombia-y se apuntan los distintos aspectos pendientes de clarificación que todavía existen, y que se deberán concretar por medio del oportuno desarrollo normativo. Pese a las desventajas que pueda tener el modelo (un posible abuso del despido por la parte empresarial, riesgo moral en el comportamiento de los trabajadores y una rebaja de la compensación por despido en los sectores en los que el empleo es más volátil y su repercusión en la redistribución de la riqueza), aporta ventajas significativas desde el punto de vista de la llamada flexi-seguridad.
\end{abstract}

\section{Palabras clave}

Fondo de capitalización, despido, prestaciones, incentivo fiscal.

\section{Códigos de clasificación JEL: K12, K22, K31}

\begin{abstract}
This paper contains the main features that characterize the new figure of «Capitalization Fund» in Spain -known as unemployment fund in Colombia- and target the various aspects pending clarification that still exist, and should realize by through timely policy development. Despite the disadvantages of the model (a possible abuse of dismissal by the employer, moral hazard in the behavior of workers and a reduction of severance pay in sectors where employment is more volatile and their impact on the redistribution of wealth), provides significant advantages from the point of view of the so-called "flexi - security".
\end{abstract}

\section{Keywords}

Severance fund, dismissal, benefits, tax incentives.

* Derivado del proyecto de investigación "Fiscalidad de los Fondos de Pensiones", del grupo de Investigación en Derecho Tributario y Financiero de la Universidad de Murcia (España).

1 Máster en Investigación Avanzada en Derecho. Profesor asociado Facultad de Derecho, Universidad de Murcia, España. Correo electrónico: norberto.miras@um.es 


\section{Introducción: el contexto económico y social español}

No se puede negar que la situación de crisis económica intensifica las reticencias empresariales, no solo a crear nuevos puestos de trabajo, sino también a mantener los hasta ahora existentes. Ante este panorama se intensifica la desconfianza en la contratación laboral estable que venía afectando al mercado laboral.

El resultado es una poco deseable situación de elevadísima temporalidad que contribuye a acentuar la inestabilidad laboral. Y es que la ausencia de un puesto de trabajo estable elimina la "vinculación afectiva" del trabajador con su empresa y hace muy difícil su implicación con los objetivos de producción, calidad y competitividad tan importantes en épocas de inseguridad económica.

No parece lógico que en pleno siglo XXI, y a pesar de los grandes avances a favor de la estabilidad del empleo introducidos en nuestro ordenamiento jurídico a través de las últimas reformas laborales, en 2012, todavía más de $90 \%$ de los nuevos contratos de trabajo suscritos cada año en nuestro país sean aún contratos temporales. Esta situación revela que el problema no es ya la amplia configuración de las causas de temporalidad previstas en el ordenamiento jurídico laboral, sino los obstáculos psicológicos que gravan la contratación indefinida. $\mathrm{Y}$ es precisamente en este contexto en el que cobra sentido cierto tipo de reforma del mercado de trabajo y de las modalidades de contrato de trabajo existentes en nuestro ordenamiento jurídico.

Como es sabido, las recomendaciones que tanto del FMI como del Banco Mundial le han hecho a España están orientadas por una parte a reducir la dualidad entre contratos indefinidos y temporales y por otra a eliminar la rigidez del mercado de trabajo como instrumentos que ayudarían tanto a evitar la destrucción de empleo, como a facilitar la creación de nuevos puestos de trabajo eliminando los obstáculos que actualmente lastran las nuevas contrataciones.

Además de otros múltiples aspectos controvertidos, relativos a la minoración de garantías laborales; las últimas reformas laborales llevadas a cabo en España intentan reducir la enorme brecha que actualmente existe entre temporalidad y estabilidad laboral, acercando el nivel de protección de la contratación temporal al que incide sobre la contratación indefinida. Así, se aprecia que cualquier forma de equiparación de los costes de extinción de los diversos tipos de contratos laborales (temporales e indefinidos) existentes hasta ahora, podría potenciar, en cierta medida, la contratación indefinida.

Precisamente para lograr este objetivo, se plantea en España la posibilidad de introducir en nuestro ordenamiento jurídico el llamado "Fondo de capitalización" que, respetando el modelo actual de relaciones laborales, serviría de puente entre la contratación indefinida y la temporal. 
Hasta ahora queda descartada en España la posibilidad de sustituir progresivamente el sistema de pensiones español, basado en el modelo de reparto por otro, sustentado en principios de capitalización individual. Y es que la responsabilidad del futuro fondo español alcanzará tan solo a la indemnización por despido (u otras vicisitudes de la vida laboral del trabajador), y en ningún caso está previsto para sustituir -sino tan solo en su caso, para complementar- las posibles pensiones de jubilación que en su momento pudiera generar el sujeto.

Se trataría de una figura jurídica, nueva hasta ahora en nuestro ordenamiento, destinada a mantener el nivel de protección del que actualmente disponen los trabajadores por cuenta ajena, que implicaría a su vez la modificación de ciertos aspectos del régimen jurídico, actualmente aplicable al contrato de trabajo (en concreto, en lo que al abono de las indemnizaciones por despido se refiere). Dicho Fondo de capitalización sería totalmente compatible con cualquier modalidad de contrato de trabajo y con cualquier tipo de relación laboral (incluyendo, salvo puntuales excepciones, a las relaciones laborales especiales).

Así, el Fondo de capitalización se ha ideado como un instrumento capaz de minorar el desembolso económico que implica para las empresas el eventual despido de sus trabajadores. Ahora bien, en España, en realidad el citado fondo no supondrá verdaderamente un "abaratamiento del despido" sino tan solo un fraccionamiento en el tiempo del pago parcial de las indemnizaciones por despido.

\section{El compromiso de creación del Fondo de Capitalización en España}

En los últimos años, en España se ha generado una expectativa de creación de una institución denominada "Fondo de Capitalización" y que se encuentra inspirada en los fondos de cesantía de otros países. Dicha expectativa viene originada por un compromiso expreso de creación proclamado por el Gobierno al dictar el RD-Ley 10/2010 y confirmado después por la Ley 35/2010 (Disposición adicional décima). Así, su efectiva creación se convierte en un mandato legal dirigido al poder ejecutivo, que por el momento y pese a haber transcurrido más de dos años desde la aprobación de la citada norma, no ha tenido desarrollo normativo alguno. Puede afirmarse que la creación del citado fondo constituirá un hito en la historia del derecho español, pues nunca hasta ahora había existido en nuestro ordenamiento una institución similar, y mucho menos ideada para implantarse de forma obligatoria y con carácter general.

Ahora bien, lo que no se puede negar es que por el momento todo acercamiento a esta nueva institución constituye poco más que una propuesta de lege ferenda. Y es que hasta ahora, la única referencia legal a esta figura es tan escueta que deja pendiente de regulación todos los aspectos esenciales relacionados con la constitución, dotación económica y funcionamiento del fondo. Ante la inexistencia hasta el momento de 
figuras similares en nuestro ordenamiento jurídico, sería apropiado atender a las experiencias de capitalización desarrolladas en otros países, con el fin de extraer ideas acerca del oportuno funcionamiento del citado fondo.

En la práctica, se ha demostrado la utilidad de esta figura en países muy diferentes, con condiciones económicas, sociales, demográficas e industriales muy distintas entre sí y muy alejadas del contexto español, pero que, correctamente empleadas, y dada la actual coyuntura socioeconómica, también puede ofrecer exitosos resultados en España. Aunque son muy numerosos los sistemas que total o parcialmente optan por introducir elementos de capitalización en la configuración de su sistema de pensiones, son únicamente tres países los que por el momento han contemplado en sus sistemas jurídicos un fondo económico específicamente destinado a proteger situaciones de desempleo: Austria, Chile y Colombia.

En concreto, este "Fondo de capitalización" compartiría grandes puntos de identidad con instituciones similares ensayadas ya desde hace años en otros países, como son el "seguro de cesantía" (Chile desde el 2002) o el "fondo de cesantía" (Colombia desde 1993) y sin duda, el actualmente tan comentado "abfertigung neu" (Austria, introducido en 2003). Es importante tener en cuenta que la práctica ha demostrado la utilidad de esta figura en países muy diferentes, con condiciones económicas, sociales, demográficas e industriales muy distintas entre sí y muy alejadas del contexto español, pero que, correctamente empleadas, y dada la actual coyuntura socioeconómica, también puede ofrecer exitosos resultados en España.

En cualquier caso, hay que tener en cuenta que en los citados países, esta institución pese a tener una finalidad similar a la que tendrá el fondo de capitalización español una vez constituido, responden a realidades socioeconómicas y demográficas muy diferentes a la española, por lo que proponer en ciertos aspectos una regulación "similar" no quiere decir en ningún momento que se vaya a producir una regulación “idéntica". Para ser verdaderamente efectivo, el fondo de capitalización en España debe dar respuesta a problemas muy concretos específicos del mercado de trabajo español y engranarse con otras figuras e instituciones españolas que comparten el mismo objetivo de garantizar una protección mínima en supuestos de inactividad del trabajador, como son la indemnización por despido, la prestación por desempleo a cargo de la Seguridad Social y, cuando proceda, la responsabilidad del Fondo de Garantía Salarial en España (FOGASA) a través del que se abona a los trabajadores el importe de los salarios o indemnizaciones derivadas de la finalización de su contrato. (Moreno, 2004).

Para poder extraer todas las utilidades del "fondo de capitalización" es necesario partir de su verdadera razón de ser: su objetivo principal debe ser reducir los altos porcentajes de temporalidad que identifican al mercado de trabajo español, y con ello, mejorar el nivel de protección laboral del que disfrutan los trabajadores por cuenta ajena. Ahora bien y, dada la situación de inestabilidad económica actual, esto es lo verdaderamente complejo, este objetivo de mejora, no puede traducirse en un 
aumento de los costes sociales de las empresas, puesto que tal efecto desincentivaría todavía más la contratación laboral en general, y la contratación laboral estable en particular. $\mathrm{Y}$ es precisamente este objetivo dual (reducir la temporalidad sin elevar los costes sociales) el que perfectamente se puede alcanzar por medio de la fórmula de capitalización que se propone alcanzar a través de esta nueva propuesta de modalidad contractual, dado que configurar este fondo como un sistema, que aunque necesite para su funcionamiento dotación económica, no implique en cambio un coste adicional para las empresas, resulta sin duda, notablemente complejo.

\section{¿Cómo funciona el Fondo?}

De las reducidas referencias legales se hace muy difícil deducir el alcance y regulación exacta que se pretende dar al citado fondo, de tal forma, pueden adelantarse ciertas cuestiones sobre las que sería interesante debatir en profundidad con el fin de dotar al futuro "fondo de capitalización" de una regulación clara, sistemática y completa.

En lo que respecta a su naturaleza jurídica, dicho fondo se ha definido "como una forma de aseguramiento universal del derecho legalmente establecido a que el trabajador reciba una indemnización a cargo de la empresa cuando finaliza su relación a consecuencia de su despido" o, en otras palabras, como "un seguro universal y contributivo a cargo de la cotización de las empresas, de la indemnización del despido, introduciendo además otros elementos que lo acercan a lo que podría llegar a ser un esquema complementario de pensiones de contribución definida" (Gómez, 2010).

Es decir, según esta noción, se trataría de una nueva figura contractual, similar a un contrato de seguro aunque no exactamente idéntico, compatible con todos los contratos de trabajo existentes, tanto de carácter temporal como fijos. A la vista de las características que se enuncian a continuación puede decirse que este fondo de capitalización tendrá vocación de indefinido (pues acompañará a cada trabajador a lo largo de toda su vida laboral) y habrá sido ideado precisamente para desplazar la enorme presencia de la contratación temporal en España (Ramos, 1996 y Penalva, 2013).

Dado que todavía no existe desarrollo normativo alguno en España, se puede adelantar que el citado fondo de capitalización se caracterizará por los siguientes rasgos:

El Fondo de capitalización implicará una fórmula de pago diferido de las obligaciones empresariales en materia de extinción de la relación laboral, evitando los desembolsos súbitos y sustituyéndolos en cambio por un sistema de aportación nominativa y periódica. De tal forma, la indemnización por despido no se modificará, pero lo que sí varía es el montante del pago final que el empresario deberá hacer en el 
momento en el que el despido se produzca, puesto que la cantidad restante en realidad la habrá abonado de forma anticipada (aunque no al trabajador en sí, sino al fondo de capitalización). O lo que es lo mismo disminuye para la empresa el coste efectivo del despido por causas objetivas, aunque el derecho del trabajador permanece inalterado (Gómez, 2010).

- Ahora bien, la constitución de dicho "fondo de capitalización" implica necesariamente la existencia de una relación contractual entre la empresa y bien una entidad bancaria, bien con la Tesorería General de la Seguridad Social (TGSS), que se ocupe de custodiar, rentabilizar, y cuando llegue el momento oportuno, reembolsar las citadas aportaciones. Es decir, con este fondo se da origen a una figura totalmente desconocida hasta ahora en el ordenamiento jurídico español cuya principal razón de ser radica en el desembolso constante, anticipado y fraccionado en pequeñas aportaciones progresivas, de los costes que hasta ahora lleva aparejada la extinción del contrato.

- El sujeto obligado a realizar las aportaciones a dicho fondo de capitalización debe ser el empresario, según Gómez (2010), pues su finalidad es sustituir o en su caso minorar, suponiendo que sea preciso, las indemnizaciones por despido que puedan corresponder a sus trabajadores. En cualquier caso, no se debe cerrar la puerta a las aportaciones que de forma totalmente voluntaria desee hacer el trabajador en su propio fondo, como mecanismo de rentabilizar su ahorro privado, y que incrementarían la cantidad económica que dicho trabajador percibiría al finalizar su relación laboral.

- Su finalidad será la de mejorar la protección del trabajador ante situaciones en las que cesa en su vida activa, o esta atraviesa tales vicisitudes que hacen aconsejable ofrecer protección económica. De tal forma, concurrirán sobre un mismo sujeto el derecho a percibir prestación contributiva por desempleo, el importe de su capitalización nominativa, e incluso, indemnización por cese (puesto que la capitalización al fondo parece intuirse que no va a suplir en su totalidad a las indemnizaciones derivadas de la extinción del contrato a iniciativa del empresario).

- Estos ingresos se mantendrían mes a mes durante toda la duración del contrato. Ahora bien, en aquellos casos en que el empresario estimase necesario proceder a una reducción de plantilla, bastaría con que entregase al trabajador una orden de pago contra el fondo capitalizador para que se produjese la rescisión automática del contrato y el paso del trabajador, también automático, en los casos en que tuviese derecho, al acceso a las prestaciones de desempleo.

- Las cantidades depositadas por el empresario en el fondo especial son cantidades individualmente asignadas a cada uno de los trabajadores con los que tiene concertado un contrato de capitalización, por lo que acompañan al trabajador durante todas las vicisitudes relacionadas con su vida laboral. 


\section{Las ventajas del modelo}

a) Para la empresa:

Las principales ventajas para la empresa se pueden resumir en la facilidad de la extinción de las relaciones contractuales sin elevar en ningún caso los costes (tanto económicos como procedimentales) derivados de dicha extinción:

- Y es que la forma de extinción del contrato de capitalización elimina los gastos económicos repentinos en caso de que fuese necesario recurrir a una reducción de plantilla.

- Al mismo tiempo, suprimiendo los trámites administrativos y judiciales en los casos de expedientes de regulación de empleo y despidos se consigue simplificar al máximo el procedimiento de extinción de los vínculos contractuales y al mismo tiempo, en muchos casos, se eliminan también otros gastos económicos indirectos $-\mathrm{y}$ relacionados con la tramitación administrativa o judicial de la solicitud de extinción-.

b) Para el trabajador:

- Crea un vínculo de unión con la empresa similar entre trabajadores temporales y trabajadores fijos, pues frente a todos existirá el deber de realizar aportaciones periódicas mensuales.

- No se modifica la configuración de ninguna de las prestaciones que actualmente ofrece el Sistema de la Seguridad Social, sino que tan solo se altera la forma de pago de una de las obligaciones que la ley impone al empresario (como es el abono de la indemnización por despido) o se reconocen nuevos derechos laborales hasta ahora inexistentes (como es el abono de las cantidades depositadas a su nombre en caso de formación o jubilación). Es decir, en la configuración del Sistema de Seguridad Social no implica en absoluto la sustitución radical del sistema actual de reparto por un sistema de capitalización individual, sino solo la introducción de algunos rasgos del sistema de capitalización sobre ciertas obligaciones empresariales inherentes al contrato de trabajo en sí, que solamente tendrán cierto reflejo -con el fin de evitar elevar los costes empresariales- sobre la obligación de cotización del empresario (Cadarso y Febrero, 2004).

Teniendo en cuenta que con la creación del fondo de capitalización por el momento no se pretende ni eliminar ni atenuar el sistema actual de reparto de prestaciones de la Seguridad Social, se superan también los mayores inconvenientes que tradicionalmente se achacan a los sistemas de capitalización puros, como son la escasa cuantía de las percepciones y la necesidad de una prolongación muy extensa de la vida activa con el fin de reunir una cantidad suficiente en el Fondo de capitalización como para hacer frente a las nuevas necesidades derivadas de la finalización de la relación laboral. 
- Desde otro punto de vista, se debe tener presente también que tras la entrada en vigor del fondo de capitalización, no existirá diferencia a la hora de contratar de forma temporal o indefinida, pues las indemnizaciones por abonar en uno u otro caso serán sustancialmente iguales. Siguiendo este argumento, la puesta en práctica del fondo de capitalización serviría para eliminar las diferencias de costes empresariales entre la contratación temporal y la indefinida, lo que en definitiva estaría sirviendo para eliminar las trabas que por el momento dificultan la contratación indefinida. Y es que aunque el trabajador indefinido, en caso de despido, tenga derecho a percibir una indemnización más elevada que la que se percibe por la mera extinción de un contrato temporal por agotamiento de su vigencia, para el empresario la elección de una u otra modalidad contractual no implicará una diferencia de costes, pues parte de la indemnización correrá a cargo del fondo de capitalización (Álvarez y Sánchez, 2000).

- Y no solo esto, el deber de capitalización del fondo, consigue también igualar entre sí a los trabajadores indefinidos, independientemente de cuál sea su antigüedad en la empresa. De esta forma, al hacer frente el propio fondo a una parte de la indemnización por despido no van a existir diferencias de coste sustanciales que inclinen a despedir en primer lugar a los trabajadores de menos antigüedad en la empresa (Velasco y Fröhlich, 2010).

- Facilita en caso de despido el percibo de una indemnización económica elevada sin dilaciones en el tiempo ni trámites judiciales.

- Permite que el trabajador conserve los depósitos acumulados en el citado fondo a lo largo de toda su vida laboral, independientemente de los puestos de trabajo que desempeñe y las empresas para las que preste servicios. Mediante esta figura no se desincentiva la movilidad voluntaria del trabajador entre distintas empresas, buscando muchas veces mejorar sus condiciones laborales. $\mathrm{Y}$ es que en otro caso, los trabajadores que deseen causar baja voluntaria en una empresa para aceptar una mejor oferta de empleo, saben que, en caso de que sean despedidos en su nueva ocupación, han perdido la antigüedad en el puesto de trabajo - que se utiliza como parámetro de cálculo de la indemnización por despido- que sí tenían en su primitivo puesto de trabajo.

- Como las cantidades aportadas al fondo de capitalización permanecen intactas a nombre del trabajador mientras dure su vida laboral, independientemente de los cambios de empresa o puesto de trabajo que se experimenten con el paso del tiempo, si llegado el momento de su jubilación, el trabajador en cuestión conserva cantidades acumuladas sobre las que no ha tenido necesidad de rescate, surgirá para él un nuevo derecho inexistente hasta ahora, a percibir, a modo de un complemento a su pensión de jubilación, el montante total de las cantidades que queden depositadas a su nombre en el citado fondo. A estos efectos, el abono del Fondo de capitalización estaría actuando como 
una medida de seguridad social complementaria. Los últimos estudios de economía aplicada han expuesto la necesidad ineludible de alargar la vida activa, combinándola al tiempo con planes de pensiones complementarios y con un aumento del ahorro, de acuerdo con Zubiri (2003). Esta fórmula de ahorro permite al trabajador conocer con exactitud la cantidad de la indemnización que va a recibir cuando se extinga su relación laboral, lo que le facilita planificar su futuro contando con un importe económico cierto (Velasco y Fröhlich, 2010).

- Debe destacarse que la puesta en marcha del fondo de capitalización (y al menos sobre el porcentaje que finalmente cubra de las indemnizaciones por despido) evitaría en gran medida el riesgo de insolvencias y moderaría la necesidad de actuación del FOGASA.

c) Para la administración:

- Al minorarse las diferencias económicas entre el despido procedente y el improcedente es lógico prever que disminuirán también en un porcentaje muy elevado los supuestos de impugnación del despido. Así, se reduce la carga de trabajo de la administración de justicia y también de los servicios de la administración laboral.

- Además, dependiendo de cómo se desarrolle la regulación del citado fondo, podría existir una segunda ventaja nada desdeñable: a través del fondo de capitalización se crea un nuevo sistema de ahorro indirecto a favor de los trabajadores que, además (respetando siempre las garantías que la norma impondrá para evitar todo riesgo de descapitalización), podrá ser a su vez invertido en diferentes tipos de activos económicos con el fin de obtener la máxima rentabilidad del capital depositado. De esta manera, y teniendo en cuenta que nada impide que la adquisición, por ejemplo, de Bonos del Estado sea una de las posibles vías de rentabilización de los depósitos del fondo, con la creación del fondo de capitalización se estaría creando al mismo tiempo una nueva forma de colocación de fondos públicos.

\section{Las desventajas del modelo}

En primer lugar, si el coste marginal del despido es cero, es probable la producción de despidos ineficientes. Se facilitaría, entonces, un posible abuso del despido por la parte empresarial. Ahora bien, su reverso sería que al eliminar las indemnizaciones por despido absolutamente también se podría desembocar en riesgo moral en el comportamiento de los trabajadores (Conde, Felgueroso y García, 2011).

Desde el punto de vista de redistribución de la riqueza y la implantación del fondo de capitalización significa una rebaja de la compensación por despido para los que realmente lo experimenten y una compensación adicional para quienes 
no lo experimenten en toda su vida activa. Así, el cambio de modelo perjudica a aquellos colectivos tradicionalmente más expuestos al despido y a aquellas empresas que, actualmente, mayor uso hagan de la flexibilidad interna (Conde, Felgueroso y García, 2011).

\section{El informe de la comisión de expertos}

El Acuerdo Social y Económico para el crecimiento, el empleo y la garantía de las pensiones, de 3 de febrero de 2011, firmado a tres bandas por gobierno, patronal y sindicatos estableció el procedimiento para la elaboración de la norma que regularía el fondo de capitalización: "la creación de un grupo de expertos integrado por seis miembros que serán consensuados por los firmantes". Este grupo elaboró el informe al que nos referimos en este apartado (Informe del grupo de expertos, 2011).

Las recomendaciones del grupo de expertos no se limitan a la posposición de la puesta en marcha del fondo, sino que incluyen otros aspectos que no han sido tomados en consideración por el Gobierno al elaborar la norma (Gimeno, 2011).

El informe señala que existen "una serie de limitaciones", que pueden llevar a recomendar el retraso de su puesta en marcha, cosa que ha ocurrido, no se sabe nada de su prometida entrada en vigor más allá del 1 de enero de 2012, en ampliación del actual período transitorio previsto en la Disposición Transitoria Tercera de la Ley $35 / 2010$.

Señala, asimismo, los posibles problemas en las contingencias cubiertas, rechazando la formación profesional y la movilidad geográfica, por la concurrencia con otros medios y la existencia de riesgo de fraude.

Por último, critican el efecto asimétrico de la implantación del sistema, pues supondría menores rentas para los trabajadores que son despedidos con mayor frecuencia, como hemos apuntado en el epígrafe de las desventajas del sistema.

Así, los expertos sentencian que "podría retrasarse su entrada en vigor hasta que la economía española mejore suficientemente", añadiendo que "incluso aunque mejorara la situación económica, los elevados recursos necesarios obligarían a plantear distintas alternativas". La economía ha mejorado, pero el asunto no se ha abordado, ni se han planteado opciones. Difícil resulta de plantear por su coste político.

\section{Costes aproximados de funcionamiento}

Uno de los elementos esenciales que caracterizarán el funcionamiento del fondo de capitalización es su dotación económica. De tal forma, una de las cuestiones más importantes que se deberán regular a la hora de emprender el desarrollo normativo de 
esta figura será relacionada con el importe de las aportaciones periódicas que deberán realizarse en nombre de cada trabajador. Y es que precisamente de esta decisión dependerá también la concreción del importe económico con que finalmente el Fondo responda cuando se produzca una de las situaciones determinantes del rescate.

Los modelos de Fondo de capitalización adoptados en otros países han optado por fórmulas muy distintas a la hora de determinar, tanto el origen de la financiación como la cuantía de las aportaciones. Por ejemplo, el Abfertigung neu, en Austria, se nutre de aportaciones empresariales que ascienden a un 1,53\% del salario íntegro bruto de cada uno de sus trabajadores. Por el contrario, las aportaciones al llamado Fondo de Cesantía en las experiencias iberoamericanas son mucho más reducidas.

En lo que respecta al futuro modelo español, por el momento, lo único que existe es un compromiso de equivalencia entre las cantidades depositadas a nombre del trabajador a lo largo de su vida laboral y el importe que finalmente se rescate. Teniendo en cuenta el alcance de este compromiso, se puede realizar la siguiente simulación:

Si se decide mantener el parámetro de los 8 días de salario por año trabajado que, a raíz de la última reforma, integra el nuevo supuesto de responsabilidad objetiva del FOGASA, el Fondo de capitalización deberá hacer frente a una cantidad económica equivalente a 8 días de salario por año trabajado en el momento en que acaezca una de las situaciones protegidas (Gómez, 2010). Y si además se anuncia que existirá equivalencia entre las cantidades aportadas y las que finalmente se rescaten, se intuye también que la aportación empresarial al fondo deberá ascender, como mínimo, a 8 días de salario al año por cada uno de sus trabajadores.

Así, una aportación de 8 días de salario por año trabajado a cargo del empresario equivale al importe mensual de 0,65 días de sueldo por cada trabajador al citado fondo de capitalización. Si esta cifra aportada se valora sobre el $100 \%$ de las retribuciones salariales, supone capitalizar al fondo un 2,1\% del salario bruto mensual de cada trabajador por cuenta ajena. Así, aplicando estos porcentajes se asegura que el fondo de capitalización cuente con una dotación económica suficiente para cubrir un porcentaje de la indemnización por despido equivalente a 8 días de salario por año trabajado, lo que implicaría el rescate total de las aportaciones empresariales realizadas a nombre del concreto trabajador.

En esta misma línea, si se opta por establecer una responsabilidad del fondo de capitalización más reducida, las aportaciones al fondo serían, en consecuencia, mucho menores. Así, "de forma similar al modelo austriaco, establecer un devengo anual para todos los trabajadores de, por ejemplo, 4 días de salario por cada año de antigüedad en el empleo, podría significar un coste equivalente a un punto de cotización sobre la masa salarial" (Gómez, 2010). 
Cuestión distinta es la de determinar qué ocurre con el posible exceso derivado de los intereses de la inversión que pudiera haberse generado durante los años de depósito. Sobre este punto deberá ser el legislador el que clarifique si estos beneficios adicionales pasarán a integrar un nuevo fondo de reserva, se distribuirán como beneficios a las entidades gestoras de los depósitos o bien, se asignarán a los propios trabajadores a modo de mejora circunstancial de los compromisos mínimos antes apuntados.

Ahora bien, al respecto no todas las opiniones doctrinales y propuestas de configuración del Fondo de capitalización son coincidentes, pues sobre este asunto se ha sugerido que las aportaciones al fondo sean bastante más reducidas.

\section{Asuntos pendientes en la configuración del Fondo}

Son muy numerosos los aspectos que deben clarificarse en relación con el funcionamiento del fondo de capitalización, como por ejemplo ¿quién ha de realizar las aportaciones al fondo y en qué cuantía?, ¿qué entidad custodia o centraliza dichas cantidades y cómo se gestionan?, ¿en qué supuestos se puede rescatar el fondo?, ¿durante cuánto tiempo se ha de aportar cantidades para tener derecho a su reembolso?

Así, entre otras, se pueden destacar las siguientes cuestiones lagunosas que por el momento rodean a la pretendida creación del fondo:

$1^{\circ}$. Parece claro que estas cantidades se ingresarían en un fondo especial, con identificación nominativa de los trabajadores beneficiarios. Lo que se desconoce todavía es la opción de administración por la que se decantará el Gobierno cuando ponga en práctica la citada medida. $\mathrm{Y}$ es que a estos efectos las opciones son muy variadas:

Podría constituirse un nuevo organismo autónomo, dependiente del Ministerio de Trabajo, destinado exclusivamente a custodiar e invertir las cantidades aportadas por las empresas para nutrir sus respectivos fondos de capitalización. Otra posibilidad es intentar utilizar los organismos ya existentes, aprovechando así un sistema de gestión y organización ya consolidado. Si se opta por esta alternativa, parecería lo más apropiado ampliar las competencias del FOGASA, convirtiéndolo también en órgano receptor de las aportaciones empresariales, esta vez individualizadas, al citado fondo de capitalización.

Por otra parte, no sería una experiencia nueva en nuestro ordenamiento jurídico, como se expone a continuación, atribuir la custodia de estos fondos específicos a la propia Seguridad Social (bien por sus entidades gestoras, bien por servicios comunes). $\mathrm{Y}$ es que, experiencias, de alguna manera similares, se vienen poniendo en práctica a través de la dotación empresarial al capital-coste, en los casos en que resulte responsable de determinadas prestaciones a favor del trabajador (art. 95. 14 TALGSS). 
En la misma línea, tampoco debe descartarse que la gestión de las citadas cantidades económicas se lleve a cabo por entidades privadas, bien se trate de Mutuas Patronales, bien directamente por entidades financiares o, incluso, compañías aseguradoras.

En concreto, como a continuación se desarrolla, debe resaltarse que es precisamente esta última opción (la gestión de la capitalización del fondo a cargo de entidades financieras) por la que se han decantado otros ordenamientos jurídicos en los que ya se ha puesto en práctica esta forma de capitalización. Y es que la práctica en otros países ha demostrado que son este tipo de entidades las que por el momento han ofrecido mayor rentabilidad al capital depositado.

Sea cual sea la alternativa de gestión por la que se decante el legislador a la hora de configurar el fondo de capitalización, lo que sí está claro es que la institución administradora debe encargarse de recoger las contribuciones periódicas, depositarlas en las cuentas individuales a nombre de los trabajadores; invertir los activos; mantener actualizadas y sin errores las cuentas individuales; proporcionar información a los afiliados en todo momento sobre el estado de su cuenta y repartir, cuando los haya, los beneficios derivados de la inversión (Zubiri, 2003).

$2^{\circ}$. Íntimamente relacionado con la recaudación y gestión de las aportaciones empresariales al fondo de capitalización está el tema de su inversión. Para que esta medida resulte rentable, debe configurarse no como un fondo de capital estático sino dinámico. Así, las cantidades depositadas mes a mes en este fondo se irían incrementando progresivamente con los intereses generados por el capital acumulado, dado que este se podría invertir en fondos públicos de alta rentabilidad o privados -autorizados al efecto por el Banco de España-. A estos efectos, cabría tomar como ejemplo el régimen de inversiones actualmente previsto para los fondos de pensiones.

Se trata esta de la única alternativa posible que garantice el valor de las cantidades depositadas (y con ello, el poder adquisitivo de los beneficiarios) permitiéndole resistir las constantes subidas de IPC, y garantizando con ello el cumplimiento de la finalidad para la que se ha configurado. Obviamente, siguiendo el mismo argumento, los beneficios acumulados por dichas inversiones deben estar totalmente exentos de impuestos para evitar cualquier merma de su importe.

- Como fórmula de estímulo al ahorro privado, como ocurre en otros países, debería admitirse que al mismo tiempo que la empresa realiza estas aportaciones al mencionado fondo especial, el trabajador decidiera que, también de sus ingresos mensuales, se descontara determinada cantidad mensual para integrar dicho fondo como ahorro personal. En ese caso, las cantidades aportadas por el trabajador gozarían de las mismas ventajas fiscales que las aportadas por la empresa (Ramos, 1996), (Penalva, 2013). 
$3^{\circ}$. Así, en el caso de que se opte por encomendar la capitalización y administración a entidades privadas (como se ha hecho en otras experiencias de nuestro entorno), deberá concretarse también cuál será la contraprestación máxima que dichos entes obtendrán por su gestión. A estos efectos, en otros países, el beneficio de las entidades gestoras se configura como un concepto variable, que se concreta periódicamente en un porcentaje sobre la rentabilidad que en cada caso se obtenga sobre el capital depositado.

$4^{\circ}$. De la escuetísima referencia legal de la que disponemos hasta ahora puede deducirse que se trata de un tipo de capitalización no sujeta a límite temporal alguno, de manera que podrá prorrogarse durante toda la vida activa de un trabajador, por extensa que esta sea, pero lo que no se ha concretado es si va a exigirse un periodo mínimo de capitalización como requisito previo para poder rescatar las cantidades depositadas.

Así, por el momento, los países que han implantado fondos con similar finalidad han optado por exigir un periodo mínimo de capitalización que, a modo de "periodo de carencia" que actúa como requisito habilitante para poder tener derecho al rescate de las cantidades aportadas (continuas o discontinuas).

$5^{\circ}$. Pero no son estas las únicas cuestiones inconclusas. Queda pendiente de concretar una materia esencial en el funcionamiento del fondo de capitalización. Y es que por mucho que el legislador se haya ocupado de adelantar que esta iniciativa se desarrollará "sin coste adicional para el empresario", no ha especificado cómo se conseguirá dicho resultado. Así, si se crea una figura nueva cuyo funcionamiento implica una aportación económica empresarial específica, si se pretende no elevar los costes sociales, obviamente deberán reducirse en otros extremos: esto es, contrarrestando esta nueva obligación empresarial con una minoración de las cotizaciones a la Seguridad Social en proporción equivalente.

Es decir, para contrarrestar estas nuevas aportaciones al Fondo, debería reducirse en cuantía significativa los porcentajes de cotización empresarial al FOGASA (dado que su función de cobertura pasará a ser mucho más reducida desde el momento en que el fondo de capitalización asegura el abono de las indemnizaciones por extinción independientemente de la situación económica que atraviese la empresa), y en menor medida, los tipos de cotización para la formación profesional o desempleo (Gómez, 2010).

$6^{\circ}$. Tampoco existe referencia alguna que permita deducir cuál va a ser la forma de abono de las cantidades depositadas al trabajador una vez se haya materializado la causa específica que da derecho al rescate del fondo. Puede pensarse tanto en un pago único (que ayude al concreto beneficiario a iniciar una nueva actividad profesional, por ejemplo, por cuenta propia, contando con el respaldo económico de las cantidades capitalizadas para hacer frente a sus nuevas inversiones), como en un devengo periódico de la cantidad total teniendo en cuenta las preferencias individuales del trabajador (García, 2008). 
No se puede negar que la situación de crisis económica que en los últimos años atraviesa España ha desencadenado un proceso muy intenso de destrucción de empleo. De tal forma, ante la gran dificultad de encontrar o conservar un puesto de trabajo por cuenta ajena, la potenciación de las distintas fórmulas de autoempleo se convierte en una razonable alternativa a través de la que se intenta compensar la dificultad actual de iniciar o mantener una actividad productiva. Y precisamente teniendo en cuenta este dato, se debería facilitar (al igual que ocurre con la prestación por desempleo) el pago único de las cantidades depositadas en el fondo de capitalización en caso de despido, con el fin de configurar un soporte económico adecuado que permita al sujeto retomar su vida profesional iniciando una actividad por cuenta propia, cubriendo con dichas cantidades los gastos iniciales derivados de la puesta en práctica de su nueva actividad (Viqueria, 1990).

Parece entonces previsible que, cuando se lleve a cabo la regulación del fondo de capitalización, se permitirá que los trabajadores, al extinguirse su contrato de trabajo, opten por percibir en un pago único la totalidad de las cantidades depositadas a su nombre en dicho fondo de capitalización, o por el contrario, materializar su abono en forma de percepciones mensuales, integrando en ella los intereses periódicos generados por las cantidades depositadas.

$7^{\circ}$. Por otra parte, para un trabajador con una extensa vida activa, si llegado el momento de rescatar su propio fondo de capitalización -por ejemplo, en caso de jubilación- tiene acumuladas cantidades muy elevadas ¿podrá rescatarlas íntegramente o existe una dotación económica máxima de la que responsabilizar el fondo? $\mathrm{O}$, ante una situación similar en las que las cantidades capitalizadas provengan de una extensa vida activa, en la que se sucedan periodos de actividad realizados para diversos empleadores, llegado el momento del despido por causas objetivas ¿qué cantidades podrá rescatar del fondo en ese caso? ¿A cuánto ascendería la indemnización que el trabajador tendría derecho a percibir en caso de despido?, y de esta cantidad ¿en qué medida responde el empresario?

Respecto a esta cuestión, parece lógico entender que por mucho que el Fondo de capitalización se haya previsto como un mecanismo de abaratamiento del despido, y por muy elevados que sean los capitales acumulados a nombre de un mismo trabajador en el fondo (bien por sucesivas relaciones laborales anteriores, bien por el éxito de la inversión de las cantidades acumuladas), nunca puede desaparecer la responsabilidad directa del último empresario de la parte que la ley determine de la indemnización por despido. Es decir, la responsabilidad del último empleador en caso de despido se mantendrá siempre, independientemente de que en el momento de dicho despido existiesen, depositadas en el fondo a nombre del trabajador en cuestión, suficientes cantidades como para hacer frente íntegramente al importe total de la indemnización por despido que el Estatuto de los Trabajadores determina para la correspondiente causa de despido. 
$\mathrm{Y}$ es que en caso contrario, el fondo de capitalización perdería la finalidad que lo caracteriza y de la que dependerá su aceptación social: introducir ventajas para ambos sujetos implicados (trabajadores y empresarios) y pasaría a configurase como un mero instrumento de minoración de los costes de despido sin reflejo alguno en el bienestar de los trabajadores.

Sobre esta última cuestión, en los casos en los que las cantidades acumuladas a nombre de un mismo trabajador lleguen a ser muy altas, tampoco debería existir límite alguno en el rescate de cantidades, con el fin de no desmotivar al trabajador que pretenda prolongar su actividad (en caso de vidas activas muy extensas) ni desincentivar el ahorro privado (en el caso de que se permita incrementar el fondo de esta manera). Y es que solo así el fondo de capitalización podrá cumplir plenamente uno de sus objetivos anunciados: permitir que, en caso de jubilación, el trabajador disponga de un soporte económico que puede llegar a ser muy elevado que complemente, en su caso, las prestaciones que pudiera recibir a cargo de la Seguridad Social (Laborda y Barrero, 2004).

$8^{\circ}$. Tan escueta es la referencia al fondo de capitalización incluida en la legislación española que ni tan si quiera se especifica qué sujetos podrán realizar aportaciones al citado fondo. Se advierte únicamente que deberá realizarse "sin coste adicional para el empresario", pero dentro de esta ambigua fórmula, caben diversas opciones:

Dado que, una de las finalidades del fondo es reducir, cuando procedan, las indemnizaciones por despido a las que tenga que hacer frente las empresas, se intuye que habrán de ser estas los principales sujetos obligados al pago periódico de las aportaciones al citado fondo. Siguiendo este razonamiento, parece descartarse la idea de que la obligación de capitalización pudiera configurarse como una obligación compartida, en mayor o menor medida, entre empresarios/trabajadores (aunque este mecanismo garantizase que esta nueva iniciativa se pudiese implantar fácilmente sin generar un coste adicional para la empresa, como promete literalmente la Ley 35/2010); pero lo que no se especifica ni se puede deducir es si se van a permitir aportaciones personales voluntarias de los propios trabajadores. Teniendo en cuenta que la finalidad del fondo de capitalización es básicamente protectora, parece lógico permitir que también los propios trabajadores (aunque esta vez de forma opcional y no obligatoria) puedan contribuir a la dotación económica de su propio fondo nominativo como fórmula de canalizar su propio ahorro privado, beneficiándose con ello de las exenciones fiscales que dicho fondo comportaría.

$\mathrm{Y}$ es que si la finalidad del fondo es la de mejorar los derechos laborales, se debería constituir como un fondo abierto no solo a aportaciones empresariales obligatorias realizadas en nombre de trabajadores por cuenta ajena sino que sería oportuno además que sea susceptible de ser completado, si el trabajador lo estima conveniente por aportaciones provenientes de su propio ahorro privado. Así, este sistema permitiría la constitución de un fondo de ahorro-que debería estar primado 
con deducciones fiscales-, que supondría en muchos casos un complemento a las pensiones básicas de la Seguridad Social (Ramos, 1996), (Penalva, 2013).

$\mathrm{Y}$ es que hoy en día las deducciones fiscales vigentes que tienen su origen en aportaciones a fondos y planes de pensiones no han ofrecido los resultados esperados y se han convertido más bien en una forma de dilatar en el tiempo el pago de impuestos, por lo que, con esta doble utilidad el fondo de capitalización podría ganar aceptación.

Y es que una ventaja muy importante de la capitalización es su rentabilidad. Así, al permitirse, bajo determinados presupuestos, la inversión en activos financieros de las cantidades acumuladas en el fondo, el trabajador, llegado el momento del devengo, puede encontrarse con que el importe total al que finalmente ascienden sus derechos acumulados es muy superior a la mera suma matemática de las cantidades ingresadas a lo largo del tiempo. Estas ventajas se habían puesto ya de manifiesto aunque aplicadas no sobre la capitalización de la indemnización por despido, sino por la hipotética capitalización de las pensiones de jubilación. Precisamente sobre este aspecto, Zubiri (2003) indica que "hay muchos que argumentan que la rentabilidad de los planes de pensiones privados es mucho más elevada que la alcanzable mediante un sistema de reparto"; y explica que "esto significa que una inversión (cotización) a 30 años de 1 euro en el sistema de reparto, genera los mismos rendimientos que 16 céntimos invertidos en un sistema de capitalización".

$9^{\circ}$. Íntimamente relacionado con la cuestión anterior queda el tema del alcance del derecho al rescate dependiendo de la vicisitud que atraviese la vida laboral del trabajador. Es decir ¿la cantidad que tiene derecho a rescatar el trabajador será siempre la misma independientemente de que sufra un despido, o por el contrario, elija suspender o extinguir su relación laboral con el fin de completar su formación, quede afectado por un supuesto de movilidad geográfica o si llega el momento de su jubilación?

$10^{\circ}$. Desde otro punto de vista: cuando se produzca una de las situaciones que generen el derecho al rescate de las cantidades aportadas, tal solicitud de reembolso ¿es opcional o resulta obligada? Es decir, una vez se produce la situación de jubilación, movilidad geográfica, necesidad de formación o despido ¿puede el trabajador optar por no rescatar las cantidades depositadas o su devengo será automático en el momento en que se produzca una de las contingencias protegidas?

Teniendo en cuenta que el Fondo de capitalización implica una aportación de cantidades nominativa a favor de cada uno de los trabajadores, no parece que exista ningún inconveniente teórico en permitir que, una vez producida una de las situaciones que generan el derecho a solicitar el rescate de cantidades, el mismo trabajador afectado opte por mantener su depósito, y reservar las cantidades aportadas para momentos de mayor necesidad. Y es que tal decisión no implicaría en ningún momento la renuncia de derechos mínimos prohibida en el ámbito laboral, sino tan solo la posposición en el tiempo de su derecho a cobro. 
Así, los trabajadores que en un momento determinado causen baja voluntaria en la empresa, si así lo desean, podrían optar por: bien solicitar el abono del fondo (obteniendo también el pago íntegro de su capital acumulado más intereses, libre también de impuestos, siempre y cuando cumpliesen el preaviso oportuno que marque en cada caso el convenio colectivo aplicable o la costumbre del lugar que exige el art. 49.1.d. del Estatuto de los Trabajadores) o bien mantener intacto dicho fondo de manera que pueda seguir integrándose en el futuro con nuevas aportaciones empresariales en el momento en el que el trabajador inicie una nueva relación laboral.

$11^{\circ}$. Debe resaltarse que el legislador utiliza una referencia genérica a los supuestos de "despido" por lo que, parece lógico deducir que en esta genérica expresión cabe incluir también no solo los despidos por causas técnicas, económicas, organizativas o de producción sino también los despidos disciplinarios o los producidos por cualquiera de las restantes causas objetivas enumeradas en el art. 52 del Estatuto de los Trabajadores, sin concretar tampoco si alcanza tanto solo a los calificados como procedentes o también a los improcedentes, o si procede equiparar al "despido" aquellas situaciones en las que la extinción del contrato se produce a iniciativa del trabajador, pero fundada en incumplimientos graves y culpables de su empleador (art. 50 Estatuto de los Trabajadores).

$12^{\circ}$. No se discute que la intención del legislador es la de exigir aportaciones empresariales al fondo de capitalización por todos sus trabajadores por cuenta ajena, sin excepción, e independientemente de la modalidad contractual que los vincule a la empresa. Lo que no queda en absoluto claro es si también los trabajadores temporales tendrán derecho al rescate de las cantidades depositadas a su nombre en el fondo de capitalización cuando su relación laboral se extinga por expiración del tiempo convenido o por el agotamiento de la causa temporal que lo originó. Y es que no se puede dejar de destacar que en la enumeración de causas de rescate que por el momento anticipa la legislación española, tan solo se utilizan las expresiones "despido", "movilidad geográfica", "formación" y "jubilación", sin incluirse en ningún momento la referencia a los supuestos de extinción del vínculo laboral por agotamiento de la duración pactada, realización del encargo, o la reincorporación del trabajador sustituido.

Pese a todo, parece intuirse que, una vez puesto en marcha el fondo de capitalización, podrían desaparecer, a efectos de cuantía del desembolso económico vinculado a la expiración del contrato, la distinción entre despido improcedente, despido por causas económicas, expiración del tiempo convenido e incluso, de la baja voluntaria del trabajador: y es que, en los casos en que se haya iniciado la capitalización al citado fondo en nombre de un trabajador en concreto, resulta previsible que, a la hora de emprender el desarrollo normativo de esta figura, se admita que cualquier forma de extinción de la relación contractual provoque el abono de las cantidades previamente acumuladas. 


\section{Conclusiones: funcionamiento óptimo del Fondo de Capitalización y la adaptación del Sistema Fiscal}

Un factor necesario para la implantación del fondo de capitalización consistiría en la modificación de ciertas instituciones propias de derecho tributario. Y es que, tal y como se ha expuesto, ayudaría a su aceptación social el hecho de abrir el fondo a la capitalización voluntaria adicional de los propios trabajadores como herramienta de canalización de su propio ahorro privado orientada a lograr, en su momento, un complemento económico adicional en los supuestos de pérdida de la condición de trabajador en activo (López, 2000).

Al respecto, y si la futura regulación permite incrementar el fondo con aportaciones individuales del trabajador, el fondo de capitalización estaría actuando como un sistema complementario de pensiones. Ahora bien, para que esta segunda utilidad del fondo de capitalización pudiera desplegar todos sus efectos, debe necesariamente reformarse el régimen de incentivos fiscales que actualmente intentan orientar las aportaciones voluntarias a planes de pensiones, hasta ahora, claramente insuficiente (González y Badenes, 2000), (Cardona, 2003), (Domínguez, 2004), (Osma, 2008).

Así, la mejor fórmula de estímulo de la capitalización voluntaria adicional del trabajador en la que se puede pensar parte de introducir una reforma en la Ley que regula el Impuesto de la Renta de las Personas Físicas y sus normas de desarrollo. En concreto, el objetivo de la citada modificación consistiría en ampliar el elenco de supuestos de reducciones a la base con el fin de dar acogida a este tipo de aportaciones individuales y voluntarias con las que un trabajador pretende complementar las aportaciones empresariales obligatorias.

Y es que, en la actualidad, en España, los incentivos fiscales al ahorro a largo plazo son poco atractivos y muy limitados, y básicamente pueden circunscribirse al hecho de que las aportaciones y contribuciones a planes de pensiones se califican de "gasto deducible", (el art. 51. 1 de la Ley 35/2006 permite reducir en la base imponible general las aportaciones y contribuciones a planes de pensiones) (Cardona, 2003).

La falta de atractivo de las aportaciones a planes de pensiones radica en:

a) Que tal incentivo fiscal no es absoluto, puesto que la misma Ley impone un límite máximo de aportaciones a dichos planes de pensiones que podrán tenerse en cuenta para calcular las citadas reducciones (art. 51.6 Ley 35/2006).

b) Y sobre todo, que en el momento del abono del capital a que daba derecho la suscripción del correspondiente plan de pensiones. El art. 17.2 de la Ley $35 / 2006$, en sus apartados $3^{\circ}, 4^{\circ}$ y $5^{\circ}$ indica que se considerarán rendimientos del trabajo,

Las rentas percibidas por los beneficiarios de planes y fondos de pensiones, las prestaciones percibidas por los beneficiarios de contratos de seguros 
concertados con mutualidades de previsión social, y las prestaciones percibidas por los beneficiarios de los planes de previsión social empresarial.

Y por tanto, incrementarán la base imponible del sujeto que las perciba en el periodo impositivo en el que se produzca su devengo. Es decir, que en el momento de su rescate tributarán como rendimientos de trabajo, con lo que solo se produce un diferimiento en el tiempo del pago del tributo.

Hay que insistir en que el legislador ha castigado la tributación de estas aportaciones a planes de pensiones, porque, por mucho de que los negros augurios que actualmente tintan el futuro del sistema de pensiones actual hagan aconsejable potenciar los sistemas complementarios de previsión social potenciando la suscripción de planes de pensiones, en los últimos años se ha endurecido todavía más el régimen fiscal que definía a ese tipo especial de rendimientos. Así, la Ley 35/2006 reguladora del IRPF introdujo ciertos cambios que eliminaban las bonificaciones que hasta ese momento todavía amparaba a este tipo de ingresos.

Tal y como indica la Exposición de motivos de la Ley 35/2006, el objeto de estos regímenes es que los individuos puedan obtener, a través del sistema público y de su plan de pensiones privado, una prestación que permita la aproximación de sus rentas al último salario percibido durante su vida laboral. Y precisamente para el cumplimiento de este objetivo, el impuesto intenta reorientar los incentivos fiscales a la previsión social complementaria hacia aquellos instrumentos cuyas percepciones se reciban de forma periódica, para lo cual se elimina la reducción del 40 por ciento anteriormente vigente para las retiradas del sistema del capital acumulado en forma de pago único.

Obviamente, el régimen fiscal que actualmente caracteriza a los planes de pensiones en España no constituye un modelo idílico pensado para incentivar al máximo el ahorro privado, sino en realidad tan solo un sistema especial que difiere en el tiempo la tributación correspondiente a cierto porcentaje de los rendimientos derivados del trabajo (se reduce la base imponible en el momento de la aportación, pero la integra de nuevo en el momento de su rescate).

Por ese motivo, cualquier fórmula de ampliación del futuro fondo de capitalización al ahorro privado (con el fin de mejorar las aportaciones empresariales obligatorias a través de las que se persigue incrementar al máximo los derechos acumulados individualmente por cada trabajador rescatables en las situaciones tasadas de despido, jubilación, formación y movilidad geográfica) debería conllevar para ser efectiva una modificación de la Ley del IRPF, ideando nuevos incentivos fiscales, obviamente mejores de los que en la actualidad definen la fiscalidad de los planes de pensiones, sin los cuales, esta segunda faceta del fondo de capitalización quedaría olvidada.

Solo si esto es así, aquellos trabajadores que durante la vigencia del contrato de trabajo de capitalización falleciesen, fuesen declarados inválidos o se jubilasen tendrían derecho, ellos o en su caso, sus herederos, al percibo íntegro de todas las 
cantidades acumuladas junto con sus correspondientes intereses libres por completo de cualquier carga impositiva.

\section{Referencias}

Álvarez, A.C., y Sánchez, F. (2000). Sistema de pensiones de reparto y formación en el trabajo: un análisis para el caso español. Hacienda Pública Española, Instituto de Estudios Fiscales, Ministerio de Economía y Hacienda. Número monográfico.

Cadarso, M. A., y Febrero, E. (2004). Sistemas de reparto, versus sistemas de capitalización: algunas reflexiones críticas. "IX Jornadas de Economía Crítica". Universidad de Castilla la Mancha. Madrid.

Cardona, M. (2003). La fiscalidad de los planes de pensiones. Universidad de Murcia, Servicio de Publicaciones. España.

Conde, J., Felgueroso, F., y García, P. J. (2011). El fondo de capitalización a la austriaca: costes y beneficios de su implantación en España. Colección Estudios Económicos, No. 6. Fundación de Estudios de Economía Aplicada. http://www. fedea.net/documentos/pubs/ee/2011/ 06-2011.pdf.

Laborda, J. L., y Barrero, F. D. (2004). ¿Por qué ahorra la gente en planes de pensiones individuales? Papeles de Trabajo del Instituto de Estudios Fiscales. Serie Economía, 27, 3-31.

García, J. M. (2008). Autoempleo: trabajo asociado y trabajo autónomo. Madrid: Tecnos.

Gimeno, D. A. (2011). El fondo de capitalización del despido y su incidencia en el sistema de pensiones. Temas Laborales, 112, 337-364.

Gómez, V. (2010, noviembre). La reforma laboral de 2010: crónica de un diálogo social frustrado. Relaciones Laborales, 21. Sección Doctrina. Editorial La Ley.

González, J. M., y Badenes, P. N. (2000). Fiscalidad efectiva de los productos de ahorro-previsión en España. Hacienda Pública Española, Extra 2000, 251-278.

Informe del Grupo de Expertos sobre el Fondo de Capitalización para los Trabajadores.

López, G. M. (2000). Pensiones privadas y ahorro agregado. Hacienda Pública Española. Instituto de Estudios Fiscales, Ministerio de Economía y Hacienda. Número monográfico.

Moreno, V. F. (2004). La capitalización de la prestación por desempleo. Civitas. Revista Española de Derecho del Trabajo, (121), 75-127.

Osma, F. B. (2008). Los partícipes y beneficiarios en la nueva regulación de los planes y fondos de pensiones. Madrid: La Ley. 
Penalva, A. S. (2012). El fondo de capitalización anunciado en la Ley 35/2010 de reforma del mercado de trabajo: aspectos básicos de su futura regulación jurídica. Valencia, España: Tirant Lo Blanch.

Ramos, V. S. (1996). El contrato de trabajo de capitalización. Las cuatro esquinas (17). Colegio de Graduados Sociales de Murcia.

Vaquero, G. A. (2002). Incentivos y desincentivos a la búsqueda de empleo: análisis económico de la prestación por desempleo. Consejo Económico y Social. Madrid.

Velasco, P. M., y Frohlich, M. (2010). Los sistemas alemán y austriaco como modelos de referencia de la reforma laboral en España. Actualidad Laboral, nº.14, 12 del soporte informático.

Viqueria, P. C. (1990). La prestación por desempleo: Valencia: Tirant lo Blanch.

Zubiri, O. I. (2003). El futuro del Sistema de Pensiones en España. Ministerio de Hacienda, Instituto de Estudios Fiscales. Madrid. 